\title{
Experiencias de la Economía Social y Solidaria en la Argentina
}

\author{
Ana Luz Abramovich \\ Gonzalo Vázquez*
}

Resumen. En este artículo intentamos reseñar brevemente las ideas centrales de la propuesta de la economía social y solidaria (ESys), y describir algunas de las experiencias desarrolladas en nuestro país que pueden conformar espacios de esta economía alternativa.

Partiendo de los múltiples aportes, tanto teóricos como desde la práctica, tomamos aquellas ideas que compartimos y que creemos permiten ilustrar esta propuesta. Trabajamos especialmente la discusión en torno a una economía alternativa y su articulación dentro del sistema imperante. Incluimos dos experiencias (empresas recuperadas y trueque) que son usualmente citadas dentro del campo de la ESys, y una tercera (el Frenapo, Frente Nacional contra la Pobreza) a la que no se suele enmarcar en este campo.

Palabras clave: economía social y solidaria, economía alternativa, experiencias, empresas recuperadas, moneda social, distribución del ingreso.

\begin{abstract}
In this article we try to outline briefly the main ideas of the Social and Solidary Economy (SSE) offer and to describe some of the experiences developed in our country that can shape spaces of this alternative economy.

Departing from multiple contributions, both theoretical and practical, we take those ideas that we share and allow us to illustrate this offer. We work specially the discussion on the joint of an alternative economy inside the dominant system. We include two experiences (recovered enterprises and "trueque", the argentine massive experiencie exchange with Social Money) that are usually mentioned inside the field of the SSE, and a third one (Frenapo, National Front against the Poverty) that is not usually included in this field.

Key words: social economy, alternative economy, experiences, recovered enterprises, social money, income distribution.
\end{abstract}

* Investigadores docentes del Instituto del Conurbano de la Universidad Nacional de General Sarmiento, Argentina. Correos electrónicos: aabramov@ungs.edu.ar, gvazquez@ungs.edu.ar 


\section{Introducción}

En el presente artículo presentaremos algunas ideas centrales de la propuesta de la economía social y solidaria (ESys) para posteriormente describir y analizar algunas experiencias desarrolladas en Argentina que pueden conformar espacios de economía alternativa.

Los objetivos de nuestro trabajo son los siguientes: 1. adoptar una posición clara en el marco del debate latinoamericano acerca de qué se entiende por economía social y/o solidaria, tanto a nivel teórico cómo político; 2 . dar a conocer de manera sintética tres experiencias argentinas que consideramos relevantes en el campo de la Esys; 3. analizar estas experiencias, para identificar qué tienen de economía alternativa, con base en la conceptualización antes desarrollada; 4. postular que estas experiencias, si bien surgen como respuestas ante la profunda crisis socioeconómica que atravesó nuestro país en los últimos diez años, muestran caminos posibles al conformar espacios de economía social y solidaria, en los que creemos que es necesario seguir experimentando y aprendiendo colectivamente.

En nuestro análisis incluimos dos experiencias (empresas recuperadas y trueque) usualmente citadas dentro del campo de la Esys, y una tercera (el Frenapo, Frente Nacional contra la Pobreza) a la que no se suele enmarcar en este campo.

Es necesario aclarar que la propuesta de la Esys no se construye sólo desde la teoría, sino que aparece expresada en documentos de distinto tipo, tanto académicos como de organizaciones sociales y de organismos del Estado.

En este sentido, partiendo de los múltiples aportes, tanto teóricos como desde la práctica, tomamos aquellas ideas que compartimos y que creemos permiten ilustrar esta propuesta.

\section{La economía social y solidaria como propuesta de economía alternativa}

La economía social y solidaria es hoy en Argentina (y en el mundo) una propuesta política con dimensiones teóricas y prácticas en desa- 
rrollo, razón por la cual todavía no es verificable ni delimitable en el plano real. Como la propuesta que es, involucra experiencias que se han puesto en marcha (antes y después de su aparición expresa como propuesta) y que han alimentado sus fundamentos. Son, entonces, múltiples las experiencias y los autores que hoy conforman el campo de la Esys.

Si bien la noción de economía social ${ }^{1}$ tiene más de un siglo, la expresión "economía social y solidaria" alude a un resurgimiento y a la transformación de esas viejas ideas. Podemos ubicar este resurgimiento progresivo en los últimos 30 años, claramente asociado a la consolidación de situaciones de exclusión social, entendida como la imposibilidad de gran parte de la población de nuestros países de reproducir su vida de acuerdo con parámetros socialmente "dignos" y, en muchos casos, hasta en términos biológicos. La cada vez más profunda tendencia a excluir a los trabajadores del empleo o a incluirlos bajo formas precarias y desprotegidas ha cristalizado en esta situación de exclusión social, que lejos de revertirse parece estar incrementando.

En este marco, la propuesta de Esys sostiene que no sólo es inmediatamente necesaria, sino también posible una transformación que contribuya a acabar con esta situación de injusticia social.

Es importante aclarar lo que no es la esys desde nuestro punto de vista. No es una propuesta de creación y promoción de emprendimientos productivos. No son simplemente las cooperativas y las mutuales. Tampoco es una propuesta enfocada tan sólo a los pobres, sino una propuesta abierta a todos los ciudadanos que además intenta asegurar la inclusión de los pobres y los excluidos.

${ }^{1}$ En términos de Coraggio (2002), puede hablarse de economía social "en tanto produce sociedad y no sólo utilidades económicas, porque genera valores de uso para satisfacer necesidades de los mismos productores o de sus comunidades -generalmente de base territorial, étnica, social o cultural- y no está orientada por la ganancia y la acumulación de capital sin límites. Además, porque vuelve a unir producción y reproducción, al producir para satisfacer de manera más directa y mejor las necesidades acordadas como legítimas por la misma sociedad". Mas allá de que consideramos que el término economía social puede ser redundante, lo adoptamos por la necesidad de abarcar un campo que ha sido denominado con ese nombre y que pone el énfasis en que las relaciones económicas son una construcción social. 
La Esys es una propuesta de construcción de una economía alternati$v a$, entendida esta última, a decir de Coraggio (2002), como una reorganización de las relaciones sociales en la producción, distribución y consumo de bienes y servicios que implique priorizar la reproducción de la vida de todos por sobre cualquier otra racionalidad.

¿Alternativa a qué? ${ }^{2}$ A lo que rechazamos de la economía capitalista, a saber:

- La desigualdad estructural de recursos y de poder que produce y reproduce para su continuidad, que no se agota en la subordinación de la clase trabajadora a la capitalista, sino también es desigualdad entre géneros, entre etnias, entre países, etcétera.

- Unas relaciones sociales empobrecidas, estructuradas por la competencia en la que la búsqueda del interés individual priva por sobre otras posibles motivaciones. Estas relaciones competitivas no se restringen al mercado, sino que van colonizando cada vez más todos los ámbitos de la vida. ${ }^{3}$

- La insustentabilidad de la producción y el consumo a nivel global, ya que destruyen el medio ambiente y las posibilidades de reproducción del propio género humano.

Una economía alternativa que rechazará necesariamente la tendencia a aceptar estas cuestiones como naturales de la vida humana, y permitirá en cambio verlas como construcciones sociales susceptibles de ser modificadas ${ }^{4}$.

\footnotetext{
${ }^{2}$ En los próximos párrafos nos basaremos en el interesante planteo que hacen Boaventura de Souza Santos y César Rodríguez en la introducción al libro Produzir para viver (2002).

${ }^{3}$ Según Gerald Cohen (citado en Danani, 2004), la sociabilidad capitalista se apoya sobre los principios de la codicia y el miedo: “Desde la codicia, las personas son vistas como fuente de enriquecimiento (me sirvo de ellos) y, desde el miedo, vistas como amenazas".

${ }^{4}$ Dice Boaventura de Souza Santos (1991): “En mi opinión, la separación entre lo económico y lo político posibilitó tanto la naturalización de la explotación capitalista como la neutralización del potencial revolucionario de la política liberal, dos procesos que convergieron para consolidar el modelo capitalista de las relaciones sociales".
} 
En este sentido, las prácticas y el pensamiento de una propuesta de economía alternativa buscan ampliar el espectro de lo posible a través de la experimentación y reflexión sobre formas de organización económica que:

- Partiendo del reconocimiento de la diversidad y dignidad de las personas y de los pueblos, promuevan relaciones más igualitarias.

- Impulsen el asociativismo ${ }^{5}$ y relaciones sociales (interpersonales y colectivas) más solidarias.

- Prioricen el respeto del medio ambiente y de las posibilidades de reproducción de la vida de todos.

En síntesis, una propuesta de economía alternativa privilegia la experimentación de prácticas y formas de sociabilidad no capitalistas, que, siguiendo a Santos y Rodríguez (2002), "apuntan a una transformación gradual de la producción y de la sociabilidad hacia formas más igualitarias, solidarias y sustentables"' (Santos y Rodríguez, 2002).

Queda claro que una economía alternativa implica una sociedad alternativa. Las propuestas de la Esys se centran en algunos ámbitos generalmente comprendidos como "económicos", pero no desconocen que éstos son parte del conjunto de las relaciones sociales en general, y que para producir modificaciones en ellos son necesarias modificaciones en todos los aspectos de la vida social.

Insistimos en que no se trata de una propuesta destinada exclusivamente a los pobres, sino a los trabajadores en general. Sobre este punto, nos parece pertinente la aclaración de Lozano (2004), en el sentido de que

...existe otra forma de pensar la economía social, que tiene que ver con pensarla no ya restringida a algo que podría denominarse economía de la pobreza, que en un sentido es en

\footnotetext{
${ }^{5}$ Según Paulo Peixoto de Alburquerque (2004), el asociativismo se puede ver como un tipo de cooperación calificada, a partir de un acuerdo ético basado en la reciprocidad, la confianza, la pluralidad y el respeto por el otro.
} 
gran medida lo que sigue siendo hasta ahora, sino pensarla como la posibilidad de plasmar en nuestro funcionamiento económico nuevas formas de producción y distribución de excedentes.

Estas prácticas alternativas, aunque no alcanzan a reemplazar al capitalismo, suelen generar dos efectos de alto contenido emancipador: a) individualmente, frecuentes y significativas mejoras en las condiciones de vida de las personas involucradas; $b$ ) socialmente, su difusión amplía los campos sociales en los que operan valores y formas de organización no capitalista. La emancipación, siguiendo a Navarro (2002), refiere a

...las posibilidades de las clases subalternas y los grupos sociales más pobres, de construir de forma autónoma sus diversas formas de asociación y representación de intereses y, más importante que eso, de penetrar en el campo de la lucha política y ejercer ahí su derecho de defender las propias reivindicaciones y buscar materializar sus demandas.

De acuerdo con Razeto (2002), estos espacios de la Esys contribuyen a una mayor democratización "en cuanto amplían socialmente el acceso al capital, en cuanto permiten a muchos participar en la gestión de empresas, y en cuanto generan ocupaciones estables no dependientes del capital". Se trata de una ampliación de la democracia al campo de lo económico, teniendo en cuenta que, como señala Santos (1991), las relaciones sociales de producción han quedado al margen del progreso que significó la adopción del ideal democrático en el campo de las relaciones políticas.

La creación de espacios de Esys, orientados hacia la reproducción ampliada de la vida del conjunto de la sociedad y no a la acumulación de capital, plantea básicamente la centralidad del trabajo en la economía en el mismo sentido en que la entiende Coraggio (2002). Esto es, el trabajador, sus capacidades y sus necesidades son la razón de ser del proceso económico, y la reproducción de su vida es vista como un fin y no como un medio. 


\section{Las experiencias de la ESys en Argentina}

En primer lugar presentamos un listado amplio de potenciales "componentes" de la Esys, tomando experiencias generalmente incluidas en la propuesta o que se han autodenominado de economía social o solidaria.

En cualquier nivel de profundidad en que se analice, no es el tipo de actividad lo que define que una experiencia pueda enmarcarse dentro de la Esys, sino las formas organizativas y de sociabilidad que se ponen en práctica en el funcionamiento real (y no sólo en el discurso de la misma). Existen prácticas de trueque en las que se actúa de acuerdo a estas formas propuestas por la Esys y otras en las que no; lo mismo ocurre con las prácticas sindicales o con el trabajo en las cooperativas, y así en cada caso.

Algunas experiencias con potencialidad para formar parte de la propuesta de la Esys en Argentina son:

- Emprendimientos comunitarios.

- Empresas recuperadas por los trabajadores.

- Microemprendimientos familiares.

- Mutuales y cooperativas.

- Espacios de intercambio con "moneda social" (trueque, en Argentina).

- Ferias populares.

- Redes de comercio justo o solidario.

- Espacios de compra conjunta.

- Microcrédito y banca social.

- Instituciones de capacitación y apoyo a todas las anteriores (incubadoras de emprendimientos).

- Movimientos piqueteros y sus actividades productivas.

- Espacios culturales territoriales.

- Sindicatos de trabajadores (ocupados o desocupados).

A continuación profundizamos en algunas experiencias recientes en nuestro país que permiten ilustrar algunas de las prácticas y formas de sociabilidad que supone la propuesta. Hacemos hincapié en 
rescatar esos aspectos de las experiencias, de manera que no detallamos las dificultades, conflictos y enfrentamientos que se han verificado a lo largo de su historia. El lector interesado en conocer estos detalles puede recurrir a la bibliografía recomendada al final de este artículo.

\section{Las empresas recuperadas y autogestionadas por los trabajadores ${ }^{6}$}

Según Martínez y colaboradores (2002), se puede definir a las empresas recuperadas como "aquellas empresas que abandonadas por las patronales, o en proceso de vaciamiento, quiebra o cierre, han sido ocupadas por los trabajadores y puestas a producir por los mismos".

Si bien el fenómeno de recuperación de empresas no es nuevo -en el caso argentino existen antecedentes de formación de cooperativas a partir de fábricas en estado terminal que se remontan a cuatro décadas atrás (Sancha, 2002)-, éste adquiere una importancia creciente a partir de 1995 y se refuerza a partir de 2001. Tal es así que el 65\% de las empresas recuperadas registradas lo fueron entre 2001 y 2003.

La cantidad de empresas recuperadas del país estaría entre 127 y 180 , según distintas fuentes. Tampoco hay datos ciertos de la cantidad de trabajadores empleados en ellas, pero se estiman entre $10 \mathrm{mil}$ y 12 mil.

La mayoría de las empresas recuperadas son manufactureras, pero también las hay comerciales, de transporte y de servicios.

En 2001 se crea el Movimiento Nacional de Empresas Recuperadas (MNER), que es una organización que se declara transversal, representativa y democrática, y que reúne a más del $60 \%$ de las empresas recuperadas.

Previa solicitud de los trabajadores, el MNER intenta apoyar los esfuerzos de poner en actividad fábricas y empresas que entran en crisis, para lo que han conformado un equipo técnico. Ese movimiento actúa como correa de transmisión para el apoyo en la organización, gestión, capacitación y puesta en actividad de entidades ocupadas, para lo cual también suscribe convenios y acuerdos con centros de

\footnotetext{
${ }^{6}$ Este apartado se basa en el trabajo de Alberto Federico-Sabaté, El surgimiento de formas asociativas en el derrumbe, ¿es posible otra economía?, GADIS, en prensa.
} 
investigación de la universidad, organizaciones profesionales, la Federación de Trabajadores de la Industria y Afines (FETIA-CTA), la Asamblea de Pequeñas y Medianas Empresas (APyME), el Instituto Nacional de Asociativismo y Economía Social, entre otros.

Sin embargo, esta asociación no es la única en su tipo. En 2003 apareció otra agrupación denominada Movimiento Nacional de Fábricas Recuperadas por los Trabajadores (MNFRT), con un menor número de organizaciones y representatividad. Las diferencias entre ambos movimientos tienen que ver con divergencias entre sus dirigentes.

El MNER y el MNFRT impulsan desde su arranque la organización de formas asociativas basadas en cooperativas de trabajo, en tanto que discuten con los que postulan la "estatización bajo control obrero" como nueva figura.

La cooperativa como figura estimula directamente la aparición de la solidaridad e igualdad en las relaciones interpersonales, al mismo tiempo que posibilita la participación en la gestión y fomenta la creatividad y el desarrollo personal de los trabajadores.

La experiencia de las empresas recuperadas genera un espacio en el que se amplía el acceso al capital, poniendo en el centro al trabajo y a los trabajadores.

Es claro que se trata de una salida defensiva por parte de los trabajadores, dado que no están apropiándose ofensivamente de grandes fábricas o firmas en un estado normal de producción y crecimiento; sin embargo, como detecta Federico-Sabaté, dar respuesta al problema social de la desocupación por esta vía involucra una redefinición de las relaciones entre capital y trabajo y pone en discusión la vigencia irrestricta del derecho de propiedad, por lo que va más allá de las dimensiones culturales, afectando el sistema institucionalizado de vínculos socioeconómicos.

$\mathrm{Al}$ respecto, Fajn y colaboradores (2003) apuntan que

...el debate generado a partir de los conflictos destrabados por los trabajadores, plantea un enfrentamiento entre los conceptos de legalidad y legitimidad. La ocupación de las empresas plantea un desafío al derecho de propiedad, pero a su vez, reclama en el marco de la legitimidad del acceso al trabajo. 
Entonces, desde el punto de vista de la emancipación, la existencia y consolidación de estas empresas no sólo permite mejoras inmediatas (aunque con crecimiento gradual) en las condiciones de vida de los trabajadores, sino también incide sobre el sistema institucionalizado de relaciones laborales y proporciona a los trabajadores una nueva herramienta de presión y negociación.

Por otra parte, el involucramiento de ambos movimientos en redes políticas y culturales más amplias nos habla también de su potencial emancipador, en el sentido de la ampliación de los campos sociales en que se actúa de acuerdo a estas prácticas y valores, así como por la posibilidad de penetrar en el campo de la lucha política.

\section{La construcción de mercados y monedas sociales}

en la experiencia del trueque

La experiencia denominada trueque consiste en la creación de mercados sociales que funcionan con una moneda social. El resurgimiento de formas de intercambio que no utilicen dinero de curso legal para realizar las transacciones resulta absolutamente razonable cuando amplios sectores de la población quedan excluidos del consumo en los mercados convencionales por no tener ingresos monetarios, aunque sí tienen recursos productivos (capacidad de trabajo o medios de producción) para producir bienes o servicios capaces de satisfacer necesidades aunque éstos no sean competitivos en los mercados. También puede ocurrir que el trueque no sólo consista en operaciones individuales y ocasionales de intercambio, sino que se extienda a redes de personas o comunidades que se organizan para, sistemáticamente, intercambiar bienes y servicios que atiendan sus necesidades recíprocas.

Se denomina prosumidores 8 a quienes participan en el trueque y tienen la doble función de: a) producir y ofrecer ciertos bienes y servi-

\footnotetext{
${ }^{7}$ Este apartado se basa en A. L. Abramovich y G. Vázquez, "La experiencia del trueque en Argentina: otro mercado es posible", ponencia presentada en el Seminario de Economía Social organizado por el Instituto de Estudios y Formación de la CTA, 4 de julio de 2003.

8 "¿Por qué se llama prosumidores a los socios de la red? Porque todos son productores y consumidores. No se puede sólo producir y no consumir, porque se acu-
} 
cios, y b) demandar otros bienes y servicios dentro de la misma comunidad de intercambio. Con este término se pretende unificar a las personas en su función de consumidores y productores, en vez de disociarlos, como ocurre en los mercados convencionales.

Un elemento fundamental del dinamismo del trueque reside en esta vinculación entre producción y consumo, al potenciar las motivaciones de las personas en relación a la producción (reactivar capacidades personales no reconocidas socialmente) y al consumo (satisfacer necesidades materiales relegadas por la falta de ingreso).

La "moneda social" es creada, distribuida y administrada por sus usuarios, que la usan para intercambios dentro de un determinado círculo, en un lugar y horario acordados. Como convención social, la moneda cumple su función en tanto los miembros de la red la acepten como representante de valor de cambio y base de los contratos.

En una primera etapa, los clubes de trueque surgieron con una doble intención: por un lado, reconocer capacidades de trabajo e intercambio de productos por parte de sectores medios excluidos del mercado laboral, y por otro, construir un movimiento alternativo a partir de prácticas apoyadas en la adhesión a ciertos valores. Para la mayoría de los primeros participantes, la intención explícita de basar las acciones en la solidaridad, en el mutuo reconocimiento interpersonal y en la autogestión responsable y participativa era la parte fundamental de la nueva experiencia. ${ }^{9}$ Entre los fundadores se encontraban activistas sociales vinculados al ecologismo que consideraban el trueque un espacio apto para difundir otras reivindicaciones y formas de intercambio, más allá del objetivo de satisfacer necesidades.

mularían papeles que no valen nada en otros espacios de intercambio. Tampoco se puede sólo consumir y no producir porque la persona no tendría cómo obtener esos productos o servicios que sólo se trocan con moneda social y no pueden ser obtenidos con dinero" (H. Primavera y C. del Valle, 2001, "Cómo comenzar una red de trueque solidario", RedLASES).

${ }^{9} \mathrm{Al}$ respecto, Coraggio (1998) señala que "un mercado es una red de intercambio material. Sin embargo, es también una red de intercambios simbólicos [...] En el caso de las redes de trueque, se pretende que la motivación por el contenido simbólico sea mucho más fuerte que por el material [...] Estas comunidades se forman con miembros de las clases medias que se ven amenazados por la exclusión y tienen ideologías y un alto capital cultural que pueden poner al servicio de un proyecto de esta naturaleza". 
Con la expansión del sistema, comenzó a participar una enorme cantidad de personas de sectores populares con necesidades urgentes sin atender, que encontraron en el trueque una manera eficaz de resolver parcialmente algunas de ellas. El objetivo excluyente de esta gran masa de participantes (muchos de ellos luego promotores y coordinadores de nuevos nodos) fue la satisfacción de necesidades acuciantes largamente relegadas por la insuficiencia de ingresos. ${ }^{10}$

En la práctica, el trueque resultó, para millones de argentinos excluidos, sin trabajo y con necesidades elementales sin atender, una

\section{Cuadro 1.}

Síntesis de la evolución de la magnitud del trueque ${ }^{a}$

\begin{tabular}{rrrr}
\hline Año & Cantidad de nodos & $\begin{array}{c}\text { Número de personas } \\
\text { involucradas }\end{array}$ & $\begin{array}{c}\text { Número de socios } \\
\text { promedio por nodo }\end{array}$ \\
\hline 1995 & 1 & 20 (mayo) & Entre 10 y 20 \\
1996 & 17 & 400 & Entre 10 y 30 \\
1997 & 40 & 2500 & Entre 10 y 100 \\
1998 & 83 & 5500 & Entre 20 y 300 \\
1999 & 200 & 20000 & Entre 40 y 400 \\
2000 & 400 & 85000 & Entre 50 y 1500 \\
2001 & 1800 & 800000 & Entre 150 y 4000 \\
2002 & 5000 & 2500000 & Entre 150 y 20000 \\
\hline
\end{tabular}

a Si bien esta información cuantitativa muestra discordancias con otros datos existentes, es la única información sistematizada y calculada de la misma forma para el total del país. Algunas fuentes llegaron a hablar de hasta 5 o 6 millones de personas relacionadas con el trueque en el año 2002. Esto incluye no sólo a las personas que participaron de los intercambios, sino también a sus familias, que estarían "relacionadas mas indirectamente" con el trueque.

Fuente: R. Gilardi, 2003, "Redes de trueque", en Documentos de Apoyo del Seminario-Taller "La economía social en Argentina. Nuevas experiencias y estrategias de institucionalización".

${ }^{10}$ En este sentido, Coraggio advierte una distinción importante: “Dado el pragmatismo predominante es probable que el sentido económico individual de participar en la red de trueque no sea constituir o reproducir una comunidad, sino resolver las propias necesidades mediante el intercambio de trabajos particulares. Por supuesto que otros significados o relaciones morales pueden ser sobreimpuestos como condición para participar, y en algunos casos ser lo que motiva la participación, pero conviene distinguir ambos aspectos". 
experiencia de integración social, económica y cultural que para muchos duró sólo unos meses, pero para otros sigue vigente.

Las distintas etapas del trueque pueden diferenciarse a partir de dos parámetros: a) la cantidad de nodos existentes y de personas intercambiando en ellos, y b) los modelos de organización de los intercambios vigentes en cada momento.

Tomando en cuenta el primer parámetro, el desarrollo del trueque puede dividirse en tres etapas:

1. Entre 1995 y 2000 tuvo un crecimiento sostenido incorporándose crecientemente nodos y personas a las redes.

2. A partir del año 2001, y sobre todo al final de ese año y principios del 2002, se da una explosión tanto de la cantidad de nodos como de la cantidad de participantes. Esto se explica principalmente por la falta de liquidez que se dio en la economía debido a ciertas medidas adoptadas por el gobierno como el "déficit cero" 11 y aún más con el "corralito". ${ }^{12}$

3. Debido a ciertos problemas internos del trueque que generan desilusión y desconfianza por parte de la gente y, en menor medida, como efecto de la disponibilidad de dinero "de curso legal" que se verificó a partir de la puesta en funcionamiento del Plan Jefes y Jefas ${ }^{13}$, a partir de mediados de 2002 comienza a

\footnotetext{
11 Así se denominó a la política de reducción del gasto público, implementada en julio de 2001, que se propuso alcanzar un equilibrio fiscal a partir de una reducción de $13 \%$ en los salarios de todos los empleados públicos, las jubilaciones y pensiones y los pagos a proveedores del Estado.

${ }^{12}$ Así fue popularmente denominada la restricción de retiros en efectivo y la prohibición de realizar transferencias al exterior, que fue aplicada el $1^{\circ}$ de diciembre de 2001 como un intento de detener el pánico bancario ante la masiva fuga de capitales ocurrida en los meses anteriores y acelerada en la semana precedente. En general, el "corralito" afectó mayormente a los medianos y pequeños depositantes, ya que los grandes ahorristas retiraron el dinero advertidos por informaciones no oficiales.

${ }^{13}$ El Plan Jefes y Jefas de Hogar Desocupados consiste en una asignación familiar mensual de $\$ 150$ (us $\$ 50$ ) para aquellos hogares cuyo jefe se encuentra desempleado y en el que existen hijos menores a cargo. Originalmente se promovía como una política universal a la que podrían "entrar" todos los hogares que se encontraran en esta situación. En los comienzos de su implementación, llegó a abarcar a 2.5
} 
decrecer rápidamente la cantidad de gente que concurre a los mercados del trueque, generando el cierre de gran cantidad de nodos.

Es en esta tercera etapa donde la experiencia masiva del trueque queda reducida a su mínima expresión, sobre todo en el Gran Buenos Aires.

Si miramos el desarrollo del trueque a partir de los modelos que guiaron su organización y forma de intercambio, también podemos distinguir tres momentos:

1. Un primer momento donde se realizaba el intercambio sin utilizar moneda. Las "compras y ventas" se anotaban en un cuadernito o planilla. Un poco después, la aparición de emisión de moneda social ("créditos") por nodo.

2. El primer acuerdo respecto de la forma de regular y controlar la emisión y distribución de créditos: el sistema solidario con control y participación de todos los socios.

3. La aparición de otro sistema de emisión y distribución, el de franquicia social, que conviviría con el sistema solidario.

Como ya se dijo, la participación en el trueque permitió -y permite aún-significativas mejoras en las condiciones de vida de las personas involucradas, en función de la promoción del desarrollo personal y creativo y de la ampliación de capacidad de satisfacción de necesidades. También promueve la solidaridad y el asociativismo, así como la permanente ampliación de los campos sociales en que se desarrollan estas formas de sociabilidad.

Creemos que lo verdaderamente innovador fue el redescubrimiento de que la moneda y los mercados son construcciones sociales. Es decir, si en el sistema regular se delegó en el Estado la responsabilidad

millones de beneficiarios. Luego se interrumpió la incorporación de nuevos hogares, produciéndose únicamente bajas. En la actualidad, el número de beneficiarios ronda los 1.5 millones, aunque hay que aclarar que ha habido transferencias hacia otros Planes. 
de construir y preservar estas herramientas, en la medida en que una parte importante de la población no se encuentra incluida en ellas, es posible organizarse y construir nuevos mercados y monedas que sí los incluyan.

La experiencia del trueque muestra que es viable crear mercados y monedas que permitan poner en funcionamiento las capacidades de trabajo y generar nuevos lazos sociales, y que esta creación puede ser impulsada y organizada por nosotros mismos como construcción social.

\section{La experiencia del Frente Nacional contra la Pobreza (Frenapo) y la propuesta del shock redistributivo}

En el año 2001 tuvo lugar en Argentina una experiencia inédita a la que consideramos dentro del marco de la esys porque integró organización popular, democracia participativa, reivindicación de la igualdad y una reorganización de la economía en función del derecho a la vida digna para todos. Esta experiencia se gestó alrededor de la idea de resolver los problemas de la indigencia, la pobreza y la reactivación de la economía de los sectores populares a partir de políticas estatales de reconocimiento universal de derechos básicos y de redistribución progresiva de ingresos.

Se trata de la conformación del Frente Nacional contra la Pobreza (Frenapo), impulsado principalmente por la Central de los Trabajadores Argentinos (CTA $)^{14}$ pero integrando a centenares de organizaciones sociales y políticas de todo el país bajo el lema "Ningún hogar pobre en la Argentina".

\footnotetext{
${ }^{14}$ En 1992, un grupo de sindicatos liderados por Cetera (docentes estatales) y ATE (Asociación de Trabajadores del Estado), afectados por las reformas en curso y disconformes con la reacción de la central sindical, decidieron escindirse de la CGT y crear la CTA. Como señala Armelino (2004): “La CTA se planteó desde su origen la conformación de una central sindical alternativa, en la que tuvieran espacio de representación distintos sectores que, en la CGT (Confederación General del Trabajo), no tenían lugar; el caso más ilustrativo es el de los desocupados, quienes quedaron sin posibilidad alguna de representación sindical y prácticamente sin ningún tipo de protección legal. La meta principal de la CTA (Central de los Trabajadores), al fin, ha sido la composición de un nuevo movimiento para disputar el poder político en la Argentina".
} 
Este movimiento tuvo sus momentos más significativos en la Marcha Federal del Frenapo que se realizó en septiembre de 2001 con el objetivo de difundir y promover la participación de la ciudadanía en la Consulta Popular que se desarrolló en todo el país entre los días 14 y 16 de diciembre de 2001, y en la que finalmente participaron con su voto más de tres millones de argentinos, avalando la propuesta del "shock redistributivo".

A decir de Armelino (2004):

Esta estrategia, que hemos denominado "la protesta-propuesta", ha sido instituida por la стА y es importante señalarla porque se trata de acciones que, así como portan un reclamo, también proponen una vía de resolución sobre aquello mismo que se está pidiendo. La marcha y la consulta popular posterior, realizada a fines de 2001, establecieron un punto de inflexión en la construcción de la Central: en un marco de crisis económica, social y política como la vivida ese año, esta organización convocó y coordinó una acción colectiva cuyo contenido fue más bien propio de una estrategia ofensiva que buscó instalar en la agenda pública no sólo un problema -la pobreza en la Argentina- sino sobre todo una solución posible de ser puesta en marcha.

La propuesta impulsada por el Frenapo, votada en la consulta popular de diciembre de 2001, articulaba tres instrumentos: ${ }^{15}$

- Un seguro de empleo y formación para todo jefe de hogar desocupado, cuyo valor debería fijarse en relación al nivel de ingresos que establece la línea de pobreza para una familia tipo.

- Una asignación universal para todos los menores de 18 años, que reemplazaría a la actual asignación familiar que se otorga sólo a los trabajadores registrados y que se haría efectiva a partir de la asistencia del menor al sistema sanitario en los primeros años de vida y al sistema educativo a partir de la edad escolar.

${ }^{15}$ Para esta exposición nos basamos en Claudio Lozano, Ana Rameri y Tomás Raffo, "La universalización de las asignaciones familiares y la actualización de la propuesta del Frenapo: distintas opciones", marzo de 2005, IDEF/CTA. 
- La universalización del haber mínimo jubilatorio para los mayores de 65 años sin cobertura previsional.

El accionar conjunto de estas tres medidas permitiría a todos los hogares ubicarse en ingresos por encima de la línea de la pobreza, al tiempo que, al descomprimir la presión sobre el mercado laboral, afirmaría condiciones materiales más favorables para el conjunto de los trabajadores ocupados.

La propuesta se enmarcaba en una estrategia de universalización de derechos (a la salud, a la educación, al empleo y a la previsión) que restituyera a la población su carácter de ciudadanos y a la par, potenciando el consumo popular como eje del mercado interno, se inscribiera como un avance en la dirección de gestar otro patrón productivo. La implementación de esta propuesta del Frenapo permitiría "contribuir a resolver el problema del empleo, dar respuesta a necesidades hoy no satisfechas, recomponer el tejido social y la organización comunitaria, incrementar los ingresos, el consumo y la actividad interna".

En diciembre de 2001, los montos necesarios para que ningún hogar quedara por debajo de la línea de pobreza (en ese entonces $\$ 490$ mensuales) ${ }^{16}$ eran de $\$ 380$ para el seguro y de $\$ 60$ de asignación por cada hijo menor de 18 años. Una actualización de la propuesta para un valor de la canasta básica de $\$ 760$ implicaría un monto del seguro de $\$ 640$, asignación por hijo de $\$ 60$ más ayuda escolar universal de $\$ 130$ y jubilación mínima universal de \$308.

$\mathrm{Al}$ analizarse la factibilidad de esta propuesta, se concluye que es viable en términos económico-financieros, por lo que se busca impulsar la voluntad política de implementarla a partir de la participación y presión popular. Como en su momento señalaron Lozano, Ramen y Raffo (2005):

La viabilidad objetiva de resolver los problemas de pobreza e indigencia de la Argentina surgen al observar que el valor

\footnotetext{
${ }^{16}$ En la actualidad, el valor de un dólar en la Argentina es de aproximadamente tres pesos (U\$\$ 1 = \$3). Durante la "convertibilidad" (1991-2001) se fijó el tipo de cambio 1 dólar $=1$ peso. Por múltiples razones sociales y económicas, este esquema explotó en la crisis de diciembre de 2001.
} 


\section{Cuadro 2.}

Costo neto anual de las políticas propuestas

y flujo de fondo disponible

Variable

En millones de \$

Universalización de la Asignación Familiar

de $\$ 60$ y de la Ayuda Escolar Anual de \$130

$8.718,8$

Seguro de Empleo y Formación de \$640

$3.585,2$

Universalización del haber jubilatorio mínimo \$308

$5.022,9$

Costo neto del total de las propuestas

$17.327,0$

Total de flujo de fondos disponible ${ }^{a}$

$17.326,4$

Fuente: Lozano, Rameri y Raffo (2005), con base en datos oficiales del INDEC, Censo 2001 y Presupuesto 2005.

a Corresponde a un estimado para el 2005, en el que se computan la subdeclaración de ingresos de la Administración Nacional, el incremento promedio de recaudación por restitución de contribución patronal a niveles de 1993 y el superávit financiero del presupuesto para ese año.

actual [en abril de 2005] del consumo de los hogares alcanzaría para que 123 millones de personas no sean pobres y para que 272 millones de personas no sean indigentes. Totales que surgen de dividir el consumo anual de los hogares por el valor actual de las canastas respectivas de pobreza e indigencia. Por ende, con sólo redistribuir el 12.7\% del consumo actual no habría pobres y con sólo repartir el $2.1 \%$ borraríamos del suelo argentino el crimen de la indigencia.

Como se puede observar, a pesar de los años transcurridos desde la formulación inicial de la propuesta, ésta no pierde vigencia aun en una nueva situación en cuanto a la recuperación del crecimiento del producto bruto. ${ }^{17}$ Al respecto, Lozano (2005) argumenta:

${ }^{17}$ De acuerdo con Lozano (2005), “luego de dos años de tasas de crecimiento significativas (superiores al 8\% anual) [...] la Argentina recupera los niveles de actividad de 1998 [...] pero con un cuadro social agravado. El desempleo es un 30\% más alto, el ingreso promedio es un $30 \%$ inferior y hay 5 millones de pobres más que en aquel momento. Si la brecha entre el 10\% más rico y el $10 \%$ más pobre de la población era de 20 veces durante los noventa, hoy es un $35 \%$ más amplia (supera las 27 veces)". 
La dinámica del mercado laboral argentino, si bien logra crear empleo, no resuelve ni la pobreza ni la desigualdad en la distribución de los ingresos. La mayor actividad económica tiene un bajo efecto sobre los ingresos de la población más postergada. Bajo las condiciones actuales y pese a la baja en el desempleo, tiende a arribarse a una nueva meseta en materia de pobreza e indigencia sustancialmente más alta que la vigente durante los noventa [...] [Resolver estos problemas] implica un replanteo de la condiciones de intervención y regulación pública sobre el funcionamiento de la economía.

En el momento de hacer una evaluación de la experiencia en términos de construcción de poder popular, el secretario general de la СТA, Víctor de Gennaro, expresaba:

El Frenapo, para mí fue una experiencia de transición. Transición entre ese tiempo de resistencia, de juntarnos para decir lo que no queremos y de construir la organización políticosocial para definir lo que queremos. Lo cierto es que fue la primera experiencia de los últimos tiempos en la que logramos juntar organizaciones sociales, religiosas, sindicales, empresariales, culturales y partidos políticos. El Frenapo rompió, por primera vez en muchos años, con [la dificultad de lograr] una experiencia organizativa conjunta. Y pasó porque pusimos un "para qué". Un "para qué" que era terminar con la pobreza en los hogares argentinos. Pusimos un instrumento que era el Seguro de Empleo y Formación y una metodología que era la consulta popular. El Frenapo hizo que nos reuniéramos todas las semanas y empezáramos a integrarnos. Para mí el Frenapo fue una experiencia de tránsito entre lo viejo y lo nuevo y es la experiencia más importante de la que participamos como СтA.

Complementando esta mirada desde las políticas de promoción de una economía social y solidaria, es necesario destacar que la movilización del Frenapo generó como consecuencia más o menos directa el retorno a las políticas sociales universales de subsidio ante la situación de pobreza. Entre ellas cabe mencionar el diseño y la 
implementación del Plan Jefas y Jefes de Hogar Desocupados lanzado a mediados de 2002 por el gobierno interino de Duhalde y el Plan Nacional de Desarrollo Local y Economía Social "Manos a la Obra" del gobierno de Kirchner. Estas políticas se diferencian notablemente de la propuesta del Frenapo (y en algún sentido resultan una parodia de la misma), pero parece razonable adjudicar a la presión popular generada en esta experiencia los avances logrados en relación a las políticas existentes al 2001.

Por otro lado, no creemos que la redistribución de ingresos sea una política alternativa a la promoción de emprendimientos autogestivos; por el contrario, lo vemos como una condición necesaria para su eficacia. Como ya hemos señalado en otros espacios (Abramovich y Vázquez, 2005), "políticas que promuevan el aumento del poder adquisitivo de sectores socioeconómicos bajos y medios serían el complemento necesario al apoyo de los emprendimientos productivos de la economía popular. No habrá mejor política de apoyo a la comercialización que una decidida y eficaz redistribución progresiva del ingreso". Por último, si bien la propuesta del Frenapo hace hincapié en la redistribución secundaria del ingreso, coincidimos con Lozano (2004) en el sentido de que lo hace dentro de una propuesta más amplia de cambio de "la matriz de organización de la economía [...] otra forma de producir y distribuir el excedente".

\section{Comentarios finales}

Desde nuestra comprensión de la propuesta de la Esys expresada en la primera parte de este trabajo, tanto esta última experiencia de organización y participación popular en busca de una reorganización más igualitaria de la economía y de garantizar la reproducción de la vida de todos, como las de las empresas recuperadas por sus trabajadores y los mercados y monedas comunitarias del trueque, son parte de esa necesaria experimentación reflexiva que implica la construcción de una economía alternativa. A esto cabe sumar que la experiencia del Frenapo resulta complementaria de las anteriores, en la medida en que una redistribución del ingreso en nuestro país no sólo es inmediatamente necesaria para atender necesidades urgentes de la población, 
sino también para posibilitar la ampliación de estos espacios de experimentación haciéndolos más viables.

Como ya han señalado Santos y Rodríguez (2002), en el marco de la propuesta de la esys pierde relevancia la disyuntiva "reforma o revolución", dado que se busca impulsar "reformas revolucionarias", es decir, iniciativas dentro del sistema que faciliten y den credibilidad a formas de organización económica y de sociabilidad no capitalista.

Se formula una propuesta alternativa, pero como se plantea desde dentro del sistema es inevitable que muchas sus las prácticas encarnen contradicciones propias del capitalismo. El impulso de actividades productivas que permitan la sobrevivencia de los trabajadores excluidos del mercado de trabajo asalariado puede verse como "funcional" al proceso de acumulación de capital al garantizar la disponibilidad de fuerza de trabajo sin asumir los costos de su reproducción. Sin embargo, lo que se busca es que la experimentación de otras formas de organización de la producción, distribución y consumo puedan dar lugar a cambios graduales en las relaciones sociales de producción imperantes.

Al constituir espacios no capitalistas dentro del sistema capitalista se da tanto articulación como competencia con el sector de empresas capitalistas. ${ }^{18}$ La relación de estos espacios con el Estado pone en juego también la necesidad de intervención y regulación por parte del mismo. Compartimos con Lozano (204) la idea de que no hay ninguna posibilidad concreta de favorecer la conformación de un sector de economía social si no es sobre la base de una activa intervención esta-

\footnotetext{
${ }^{18}$ Cabe aquí la aclaración de Coraggio (1948): “Dentro de los emprendimientos se requiere apuntalar la competitividad de la producción, para lo cual resulta necesario establecer mecanismos de control de la calidad de esa producción, así como el orgullo por el producto del trabajo propio, la valoración de la creatividad, la vinculación honesta con el usuario, la búsqueda de los términos justos del intercambio y la valoración de la cooperación. Se necesita desarrollar sistemas de información que permitan tomar correctamente las decisiones respecto de la actividad económica, así como de la inserción del emprendimiento en la comunidad y su articulación en diversas redes". En este sentido, también es pertinente la aportación de Melo Lisboa (2044): “... dado que no rechaza totalmente el mundo moderno, sino que busca ser una alternativa de vida al interior del mismo, la economía solidaria no teje redes cerradas, pues quiere superar la sociedad de mercado a través del propio mercado".
} 
tal, alterando la matriz de organización que la economía tiene hasta el momento. Esto implica, como señala Hinkelammer (2004), recuperar el derecho político de la intervención en los mercados enfrentando el poder de los grandes monopolios.

Creemos que las tres experiencias analizadas fortalecen algunas tendencias que se observan -incipientes- en la realidad sociopolítica actual de Latinoamérica hacia una mayor intervención y regulación social de los mercados, la valoración de iniciativas asociativas y autogestionadas en la búsqueda activa de nuevos escenarios, y el reconocimiento social y estatal de un cambio necesario en la jerarquía de derechos en favor de la vida y el trabajo y en contra de la libertad sin restricciones del capital y la propiedad privada. Tendencias todas ellas no suficientes, pero necesarias para la concreción de un proyecto de otra economía.

\section{Bibliografía}

Abramovich, A. L. y G. Vázquez, 2003, “La experiencia del trueque en Argentina: otro mercado es posible", ponencia presentada en el Seminario de Economía Social organizado por el Instituto de Estudios y formación de la CTA, 4 de julio de 2003.

2005, "Reflexiones sobre las formas de promoción y apoyo a emprendimientos productivos", en Revista Medio Ambiente y Urbanización, núm. 61, IIED-AL, Buenos Aires, febrero de 2005.

ACTA, 2002, "Jugarse por lo que uno cree", nota publicada por la Agencia de noticias de la CTA. http://www.cta.org.ar/ NewsPubN/Archives/8/week2.shtml

Arévalo, R. y T. Calello, 2003, "Las empresas recuperadas en Argentina: algunas dimensiones para su análisis", trabajo presentado en el Segundo Congreso Argentino de Administración Pública, Córdoba, noviembre.

Armelino, Martín, 2004, "Algunos aspectos de la acción colectiva y la protesta en la CTA y el MTA", en Laboratorio, núm. 15, Buenos Aires, primavera de 2004.

Coraggio, José Luis, 1998, Economía popular urbana: una nueva perspectiva para el desarrollo local, Cartillas 1, Programa de Desarrollo Lo- 
cal, Instituto del Conurbano, Universidad Nacional de General Sarmiento, Buenos Aires.

2002a, "La economía del trabajo como perspectiva alternativa al problema del empleo", en Javier Lindemboin (comp.) Metamorfosis del empleo en Argentina, Cuadernos del CEPED, núm. 7. , 2002b, "La economía social como vía para otro desarrollo social", en De la emergencia a la estrategia: más allá del "alivio de la pobreza",. Espacio Editorial, Buenos Aires, 2004.

Danani, Claudia, 2004, "El alfiler en la silla: sentidos, proyectos y alternativas en el debate de las políticas sociales y de la economía social", en Política Social y Economía Social. Debates fundamentales, Fundación OSDE-Altamira-UNGS.

Fajn, G. et al., 2003, Fábricas y empresas recuperadas, Centro Cultural de la Cooperación, Buenos Aires.

Federico-Sabaté, A., El surgimiento de formas asociativas en el derrumbe: ¿es posible otra economía?, GADIS, en prensa.

Gaiger, L., 2000, "Sentido e possibilidades da economia solidaria hoje", en Gabriel Kraychet, Francisco Lara y Beatriz Costa (orgs.), Economia dos setores populares: entre a realidade e a utopia, Editora Vozes, Petópolis.

,2004, "Emprendimientos económicos solidarios", en Antonio Cattani (comp.), La otra economía, Fundación OSDE-AltamiraUNGS, Buenos Aires.

Gilardi, R., 2003, "Redes de trueque", en Documentos de Apoyo del Seminario-Taller "La economía social en Argentina. Nuevas experiencias y estrategias de institucionalización", Jefatura de Gabinete de Ministros-Universidad Nacional de San Martín.

Hinkelammert, Franz, 2004, "La vida es más que el capital. La democracia de ciudadanos y el proyecto de la sociedad en la que quepan todos los seres humanos", en Revista Pasos, núm. 113, Departamento Ecuménico de Investigaciones, San José, Costa Rica.

IDEF/CTA 2002, "Shock distributivo, autonomía nacional y democratización. Aportes para superar la crisis de la sociedad argentina", en http:// www.institutocta.org.ar/ 
Laville, Jean-Louis, 2002, Una tercera vía para el trabajo, Ediciones Mensajero, Bilbao.

Lozano, Claudio, 2004, Exposición en el Taller sobre Desarrollo Local y Desarrollo Regional, organizado por el Espacio de Economía Social del Instituto de Estudios y Formación de la CTA, en el marco del Foro Temático Otra Economíia es Posible: la Economia Social y Solidaria, del Comité Movilizador Buenos Aires del Foro Social Mundial, Facultad de Ciencias Sociales, Universidad de Buenos Aires, 4, 5 y 6 de junio de 2004.

, 2005, "Los problemas de la distribución del ingreso y el crecimiento en la Argentina actual", IDEF/CTA, febrero de 2005. Ana Rameri y Tomás Raffo, 2005, “La universalizacion de las asignaciones familiares y la actualizacion de la propuesta del Frenapo: distintas opciones", IDEF/CTA, marzo de 2005.

Mance, Euclides, "La colaboración solidaria como una alternativa a la globalización capitalista", artículo consultado el 15 de marzo de 2003 en www.trueque-marysierras.ogr.ar/biblioteca2.htm 2001, A revoluçâo das redes, Editora Vozes, Petrópolis.

Martínez, O. y F. Vocos, 2002, "Las empresas recuperadas por los trabajadores y el movimiento obrero", en E. Carpintero y M. Hernández, Produciendo realidad, Topía Editorial, Buenos Aires.

Melo Lisboa, Armando, 2004, "Mercado solidario", en Antonio Cattani (comp.), La otra economía, Fundación OSDE-Altamira-UNGS, Buenos Aires.

Navarro, Zander, 2002, "Mobilizaçâo sem emancipaçâo-asa lutas sociais dos sem-terra no Brasil", en Boaventura de Souza Santos (org.), Produzir para viver: os caminhos da produçâo nâo capitalista, Civilização Brasileira, Brasil.

Palomino, 2002, "El movimiento de trabajadores de empresas recuperadas", Revista Sociedad, núms. 20/21, FCS-UBA, verano, Buenos Aires.

Peixoto de Albuquerque, Paulo, 2004, "Asociativismo", en Antonio Cattani (comp.), La otra economía, Fundación OSDE-AltamiraUNGS, Buenos Aires. 
Primavera, H. y C. del Valle, 2001, "Cómo comenzar una red de trueque solidario", Red Lationamericana de Socioeconomía Solidaria (RedLASES).

Razeto Migliaro, Luis, 2002, “La economía solidaria como radicalización de la democracia", ponencia presentada en el II Foro Social Mundial de Porto Alegre en el Seminario sobre la Economía de Solidaridad. Disponible en www.economiasolidaria.net

Sancha, J., 2003, "Recuperación de fuentes de trabajo a partir de la autogestión de los trabajadores", ponencia presentada en el Seminario de Economía Social organizado por el Instituto de Estudios y Formación de la CTA, 4 de julio de 2003.

Santos, Boaventura de Souza, 1991, Estado, derecho y luchas sociales, ILSA, Bogotá, Colombia.

___ y César Rodríguez, 2002, Producir para viver. Para ampliar o canone da produçao, Civilizaçao Brasileira, Río de Janeiro.

Singer, Paul, 2002, Introduçao à Economia Solidaria, Fundaçao Perseu Abramo, Sao Paulo. 